\title{
Evolutionary history of the Corallinales (Corallinophycidae, Rhodophyta) inferred from nuclear, plastidial and mitochondrial genomes
}

Lucie Bittner^1, Claude E. Payri ${ }^{b}$, Gavin W. Maneveldtc, Arnaud Couloux ${ }^{d}$, Corinne Cruaud ${ }^{d}$, Bruno de Reviers a, Line Le Galla

a UMR 7138 "Systematique, Adaptation, Evolution", Departement "Systematique et Evolution", Museum National d'Histoire Naturelle, CP 39, 75231 Paris cedex 05, France

b U227 "Biocomplexite des ecosystemes coralliens", Institut de Recherche pour le Developpement, B.P. A5, 98848, Noumea Cedex, Nouvelle-Caledonie, France

c Department of Biodiversity and Conservation Biology, University of the Western Cape, Private Bag X17, Bellville 7535, South Africa

d Genoscope, Centre National de Sequengage, 2 Rue Gaston Cremieux, CP5706, 91057 Evry Cedex, France

\section{Abstract}

Systematics of the red algal order Corallinales has a long and convoluted history. In the present study, molecular approaches were used to assess the phylogenetic relationships based on the analyses of two datasets: a large dataset of SSU sequences including mainly sequences from GenBank; and a combined dataset including four molecular markers (two nuclear: SSU, LSU; one plastidial: psbA; and one mitochondrial: COI). Phylogenetic analyses of both datasets re-affirmed the monophyly of the Corallinales as well as the two families (Corallinaceae and Hapalidiaceae) currently recognized within the order. Three of the four subfamilies of the Corallinaceae (Corallinoideae, Lithophylloideae, Metagoniolithoideae) were also resolved as a monophyletic lineage whereas members of the Mastophoroideae were resolved as four distinct lineages. We therefore propose to restrict the Mastophoroideae to the genera Mastophora, Metamastophora, and possibly Lithoporella in the aim of rendering this subfamily monophyletic. In addition, our phylogenies resolved the genus Hydrolithon in two unrelated lineages, one containing the gener- itype Hydrolithon reinboldii and the second containing Hydrolithon onkodes, which used to be the generitype of the now defunct genus Porolithon. We therefore propose to resurrect the genus Porolithon for the second lineage encompassing those species with primarily monomerous thalli, and trichocyte arrangements in large pustulate horizontal rows. Moreover, our phylogenetic analyses revealed the presence of cryptic diversity in several taxa, shedding light on the need for further studies to better circumscribe species frontiers within the diverse order Corallinales, especially in the genera Mesophyllum and Neogoniolithon. 
Keywords: COI, Corallinales, Mastophoroideae, LSU rDNA, Phylogeny, Porolithon, psbA, SSU, rDNA

\section{Introduction}

The Corallinales, along with the Sporolithales (Corallinophycidae, Rhodophyta), is an intriguing red algal order characterized by the presence of calcite in their cell walls. This calcification capacity confers them a crucial ecological role especially in coral reef construction (Steneck 1986; Payri 1995; Amado-Filho et al., 2007) and a paleontological significance (Payri and Cabioch, 2003; Cabioch et al., 2008) due to their strong ability to become fossilized (Aguirre et al., 2010). However, coralline identification is largely hampered by phenotypic plasticity depending on environmental conditions (Steneck and Adey, 1976; Woelkerling et al., 1993a; Maneveldt and Keats, 2008) as well as the need for decalcification prior to the observation of anatomical features.

The taxonomy of the coralline algae has been extremely convoluted (e.g. Lamy and Woelkerling, 1998). The order Corallinales was formally segregated from the Cryptonemiales by Silva and Johansen (1986), who considered it with the same delimitation as the family Corallinaceae. The comprehension of the Corallinales affinities within the Florideophyceae, as well as their infra ordinal diversity, were greatly improved thanks to the advent of phyloge- nies inferred from molecular data. Molecular phylogenies based on ribosomal operons (Saunders and Bailey, 1997; Harper and Saunders, 2001a), confirmed that the Corallinales form a genetically divergent lineage among the remaining floridophycean orders. Interestingly, all taxa within the Corallinales possess primary pit plugs with two cap layers, corroborating Pueschel's (1989) hypotheses on the taxonomic importance of pit plug ultrastructures. The addition of a novel nuclear marker EF2 (elongation factor 2) (Le Gall and Saunders, 2007), as well as the mining of data available from GenBank (Verbruggen et al., 2010), greatly improved the resolution of the red algal relationships: the Coralli- nales and Rhodogorgonales were resolved and confirmed as strong allies within a lineage distinct from the remaining florideo- phycean lineages, sister to a lineage gathering together the Ahnfeltiophycidae and the Rhodymeniophycidae. The Corallinales and Rhodogorgonales were thus assigned to a new subclass, the Corallinophycidae, which members are characterized both by primary pit plugs with two cap layers and the presence of calcite (Le Gall and Saunders, 2007).

Within the Corallinales, several classifications have been proposed based solely on morphological and anatomical characters (e.g. Cabioch, 1972, 1988; Johansen, 1976; Woelkerling, 1988), which differ mainly by the weight given to vegetative and/or reproductive characters. Cabioch (1972) emphasized the importance of vegetative features (e.g. presence vs. absence of cell fusions and secondary pit connections) whereas Woelkerling (1988) considered mainly reproductive features. Bailey and 
Chapman $(1996,1998)$ published the first molecular phylogenies of the Corallinales and confirmed the evolutionary scenario hypothesised by Cabioch (1988) that the geniculate forms had evolved independently in distinct lineages of the Corallinales. Based on their molecular data, Harvey et al. (2003) proposed the recognition of a new family within the Corallinales, the Hapalidiaceae, for taxa which tetrasporangia produce zonately arranged spores, but also which tetrasporangia develop in conceptacles beneath multiporate pore plates, and furthermore which produce tetrasporangial apical plugs. Within the Hapalidiaceae, Harvey et al. (2003) recognised three subfamilies: the Austrolithoideae, Choreonematoideae and Melobesioideae. Each of these subfamilies is defined by two morphological and anatomical characters: the presence or absence of cell fusions between cells of contiguous vegetative filaments and nature (cellular vs. acellular) of pore plate construction of the tet- rasporangial conceptacle (Supp. Mat. 1). The Melobesioideae are characterized by the presence of cell fusions between cells of contiguous vegetative filaments whereas the Austrolithoideae and Choreonematoideae are devoid of this feature. The Choreonematoi- deae in turn differs from the two previous subfamilies by the composition of the multiporate tetrasporangial conceptacle pore plate that is acellular at maturity, and composed only of a calcium carbonate, sievelike matrix (Broadwater et al., 2002).

In addition, Harvey et al. (2003) conducted a thorough revision of the subfamilial circumscription among the living Corallinaceae and recognised four subfamilies, namely the Corallinoideae, Litho- phylloideae, Mastophoroideae and Metagoniolithoideae. Each of these subfamilies is defined by a combination of morphological and anatomical characters (Supp. Mat. 1).

Along with the Corallinaceae and Hapalidiaceae, Harvey et al. (2003) recognized the Sporolithaceae, proposed by Verheij (1993) for taxa characterized by cruciately divided tetrasporangia that develop individually in sori (calcified sporangial compartments) and which sori produce apical pore plugs. Le Gall et al. (2010) subsequently elevated this family to ordinal rank (the Sporolithales) because of its alliance in molecular phylogenies with the Rhodogorgonales in addition to its unique tetrasporangial development. Consequently, the Corallinales currently encompass two families namely the Corallinaceae and Hapalidiaceae, which share zonately divided tetrasporangia.

Phylogenies of the Corallinales published thus far suffer from a lack of resolution at the subfamily level, which was likely due to limited taxon sampling and the lack of signal of the molecular marker chosen to infer the phylogeny. Most of the coralline algal phylogenies published so far included only a few members (one or two) of the Mastophoroideae, whereas this subfamily currently comprises eight genera (Harvey et al., 2003). To circumvent this poor taxa sampling, Bailey et al. (2004) included in 
their analyses six species belonging to three genera (Hydrolithon, Neogoniolithon and Spongites) of the Mastophoroideae and resolved the Mastopho- roideae as polyphyletic lineages. Unfortunately they did not include any representatives of the genus Mastophora (type genus of the subfamily) preventing them from proposing a revision of this subfamily. In addition, all the coralline algal phylogenies published until 2008 were inferred from a single marker, the SSU. Broom et al. (2008) proposed the plastidial gene $p s b A$ (encoding for the D1 protein of photosystem II) as a novel marker to be used in combination with SSU data to improve the phylogenetic resolution within the order. Walker et al. (2009) also showed the relevance of using a mitochondrial marker to get new insights into the genetic diversity at a lower taxonomic level; i.e. in this study the barcode marker (5' end of the COI, the cytochrome $c$ oxidase subunit I) was sequenced for members of the Corallinoideae subfamily. Although promising and easy to amplify (Bittner et al., 2010), these two novel markers ( $p s b \mathrm{~A}, \mathrm{COI}$ ) were studied for a restricted sample of morphologically identified taxa and their contribution to improve the phylogenetic resolution at the scale of the order Corallinales had yet to be tested.

The aim of the present study was thus to improve the resolution of the Corallinales infra-ordinal phylogenetic relationships. Toward this aim, two datasets were built: (1) a taxa rich SSU dataset including most sequences available in GenBank; and (2) a multi- marker dataset including two nuclear loci (SSU and LSU), one plas- tidial ( $p s b \mathrm{~A})$ and one mitochondrial (COI) genes. In order to meaningfully assess the delineation of the subfamily Mastophoroideae, we included up to 35 mastophoroid taxa, including representatives from the type genus Mastophora.

\section{Material and methods}

\subsection{Collections and identification of taxa}

Coralline algal samples were collected from a broad geographical range (Table 1) by snorkel or SCUBA diving. Specimens were dried as soon as possible after collection by placement in desiccant silica gel. Identification of the specimens was performed to the lowest possible taxonomic level possible through observation of vegetative and reproductive features on histological sections.

\subsection{DNA extractions, PCR amplifications and sequencing}

Coralline algal tissue was carefully removed under a dissecting microscope from part of the thallus free of epiphytes by scraping the surface with a razor blade. The excised tissue was ground using a mortar and pestle. DNA was extracted using the DNeasy Plant Kit (Qiagen Gmbh, Hilden, Germany) following the manufacturer's instructions after the lysis step, which was performed using an extraction buffer optimised for red algae (Saunders, 1993). 
The SSU (18S) locus was amplified with two polymerase chain reactions (PCR) using primers G01/Go8 and G04/Go7, and was se- quenced using the PCR primers, as well as the internal primers G10, Go6 following protocols of Saunders and Kraft (1994, 1996) and Harper and Saunders (2001a). LSU (28S) was amplified as three overlapping fragments using primers To1N/T20, To4/To8 and To5/T15, and using the PCR primers and the internal primers T10, T16N, T19N, T22, T24, T25, T30, T33, following protocols of Harper and Saunders (2001a) and Le Gall and Saunders (2010). The $p s b A$ was amplified and sequenced using primers psbAF1 and psbAR2 (Yoon et al., 2002) and the COI was amplified and sequenced using primers designed to amplify the barcode region in red algae: GazF1 and GazR1 (Saunders, 2005). PCR products were purified and sequenced by Genoscope (http://www.genoscope.fr). 


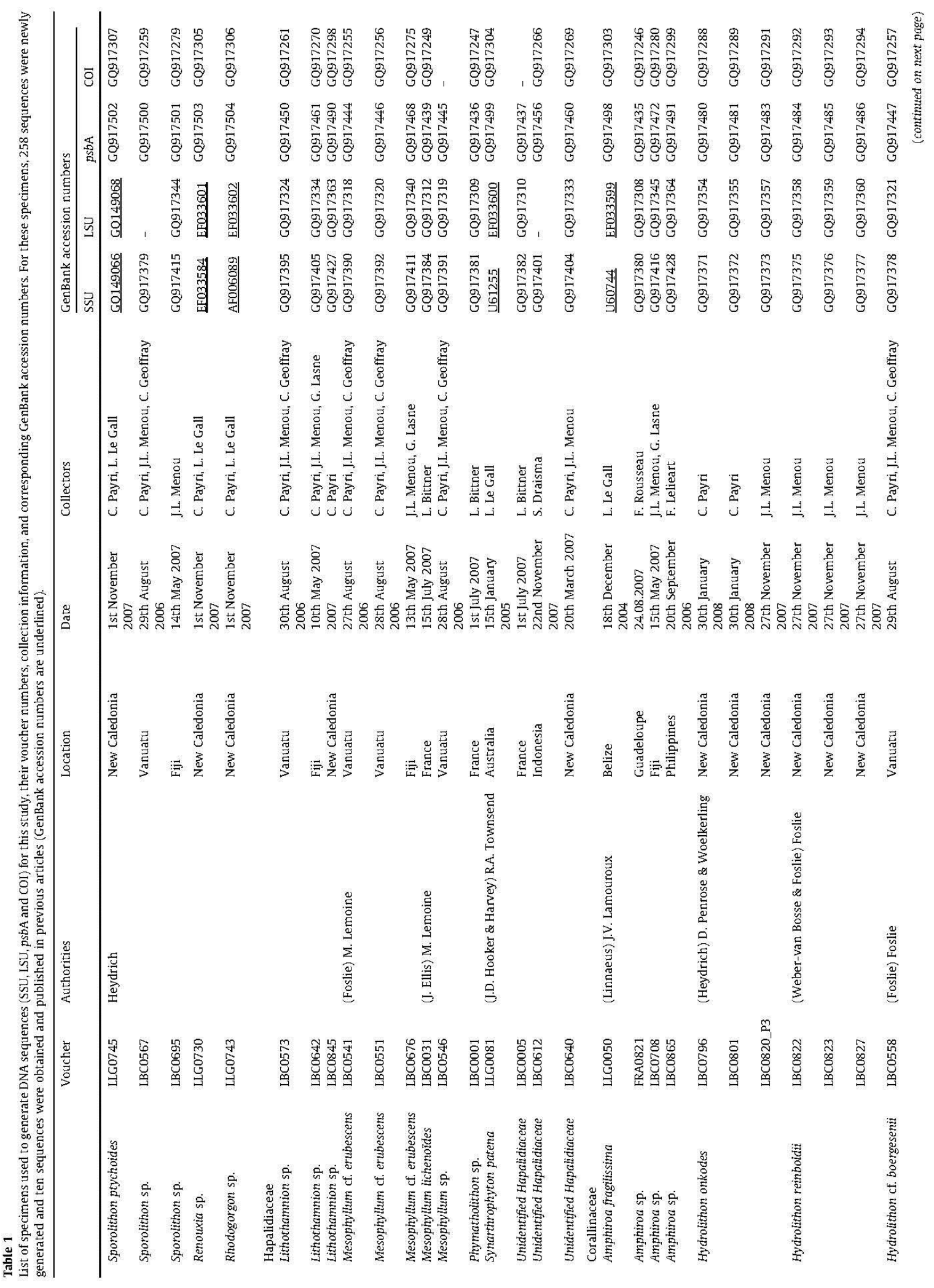




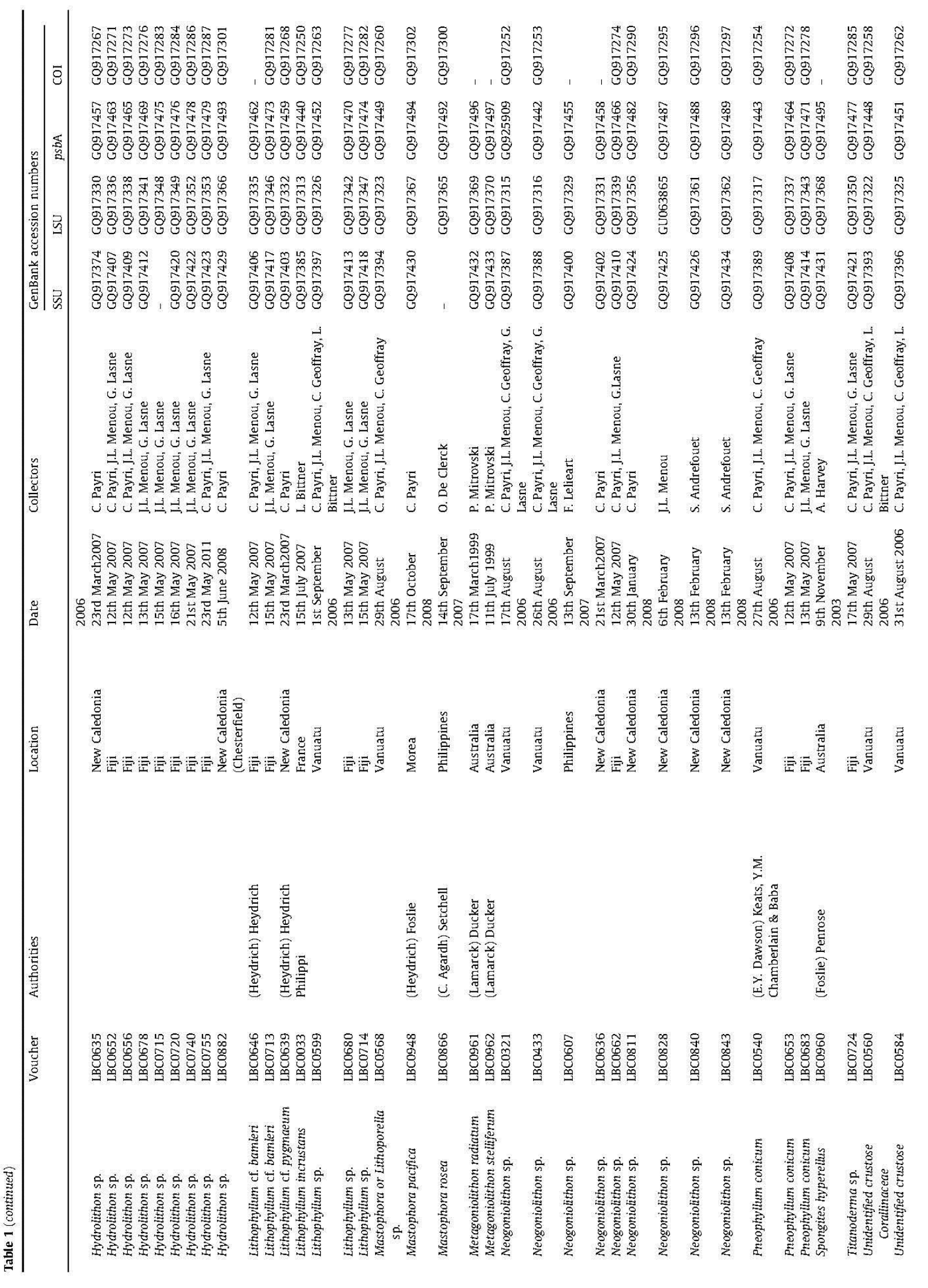




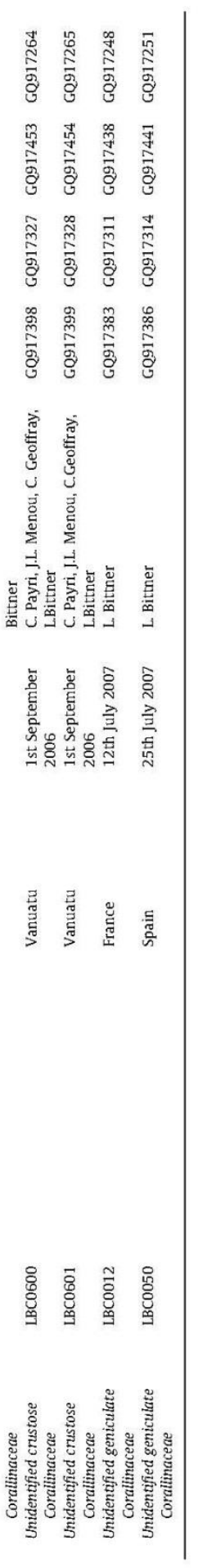




\subsection{Datasets building}

Sequences were edited and contigs were assembled using Sequencher TM 4.1 (Gene Codes Corporation, Michigan). Alignments were done with the assistance of MacClade version 4.06 (Maddison and Maddison, 2003) and adjusted by eye. Two datasets were built to assess infra-ordinal relationships within the Corallinales. Dataset 1, which included 191 taxa (of which 180 belong to the Corallinales), was built in order to assess relationships among the highly diverse taxa of the Corallinales by pooling the SSU sequences (61 Corallinales, Table 1) obtained in the present study with a large selection of SSU sequences available from GenBank (119 Corallinales, Tables 1 and 2). Dataset 1 encompassed representatives from each subfamily within the Corallinales (except for the Austrolithoideae) as well as "uncultured eukaryotes", which were resolved within the Corallinales. Dataset 2 included four loci (SSU, LSU, $p s b A, \mathrm{COI}$ ) and 70 taxa of which 65 belonged to the Corallinales. Dataset 2 was built to improve the phylogenetic resolution among representatives of each of the subfamilies within the Corallinales. Both datasets were rooted with members of the Rhodogorgonales and Sporolithales, which were resolved as sister groups to the Corallinales in recent studies (Le Gall et al., 2010). Alignments and datasets are available online in Annexes

\subsection{Partitioning strategy, model choice and phylogenetic analyses}

Dataset 1 included only SSU sequences and thus only one unique partition was considered. The software jModelTest (Posada, 2008), was used to select for this dataset as it was shown to be the best suited model of evolution, following the Akaike Information Criterion (AIC, Akaike, 1973), the second-order corrected AIC (AICc, Hurvich and Tsai, 1989), and the Bayesian Information Criterion (BIC, Schwarz, 1978). With dataset 1 , the best model chosen by each criterion was the GTR + G8.

Dataset 2 included ribosomal loci (SSU, LSU) and encoding markers (psbA, COI). An appropriate partitioning scheme was chosen by applying a partitioned model selection pipeline, implemented in the software 'Partitioned Model Tester' (PMT, version 1.0.1). The PMT software (developed by Heroen Verbruggen, downloadable on his webpage: http://www.phycoweb.net/) is a Perl program that evaluates different partitioning strategies and models of sequence evolution for a given alignment. Akaike and Bayes- ian information criteria (AIC, AICc, BIC) were calculated with PMT for five partitioning strategies and for 36 models of sequence evolution (details in Supp. Mat. 2). Finally, the preferred combination partitioning strategy was that in which dataset 2 was partitioned by marker and by codon position within protein coding genes (8 partitions: 1 with SSU, 1 with LSU, and 3 partitions for each positions of $p s b \mathrm{~A}$ and COI). With dataset 2, the best model chosen by the AIC was the GTR + G8, and the best model chosen by the AICc and BIC was the GTR $+\mathrm{G}_{4}+\mathrm{I}$. 
Subsequent to the partitioning strategy and the model choice steps, phylogenetic analyses of Maximum likelihood (ML) were performed using the RAxML software version 7.2.0 (Stamatakis, 2006) on the Cipres portal 2 (CIPRES cluster). Analyses were performed for each dataset at least four times, with different starting trees, using the partition strategy and the model of sequence evolution detailed in the previous paragraph. With dataset 2, for each partition, the GTR + G4 + I was selected.

For dataset 1 and dataset 2, bootstrap supports (BS) (Felsenstein, 1985) analyses consisting of 2000 replicates, were calculated with the RAxML rapid bootstrap algorithm (Stamatakis et al., 2008) on the same portal. With dataset 2, prior to inferring phylogeny with combined markers, analyses were performed for each included loci and no strongly conflicting nodes were found by visually comparing topologies (except for psbA and COI tree with the specimens LBC0796, LBCo801 and LBCo820, see Supp. Mat. 3). With reference to these latter three specimens, psbA and COI trees strongly disagree, whereas LSU and SSU trees show the same phylogenetic relationships hypotheses than the plastidial tree with low BS support. These dissimilar phylogenetic patterns could be due to incomplete lineage sorting, or processes of hybridization/recombination. Considering this conflict, the COI sequence from LBCo796 was removed from the concatenated dataset (dataset 2) before performing the analyses. 
Table 2

List of GenBank accession numbers of the SSU sequences included in dataset 1 . When more than one sequence was allocated to the same species name, information about the sampling locality (when indicated in the original publication) or the voucher number were retained in the labelling of the specimen, to help the reader identify the taxa in Fig. 1. AUS = Australia NZ = New Zealand $\mathrm{SAF}=$ South Africa. NB. Classification and more specifcally genus and species names have been reported in the table herein as they are indicated on GenBank.

\begin{tabular}{|c|c|}
\hline Order, family, subfamily, species, voucher number [details on sampling locality] & GenBank accession no. (SSU sequences) \\
\hline \multicolumn{2}{|l|}{ Sporolithales } \\
\hline Heydrichia homalopasta [AUS] & AF411629 \\
\hline Heydrichia homalopasta [NZ Chatham I] & EF628210 \\
\hline Heydrichia woelkeringii & U61253 \\
\hline Sporolithon durum [AUS] & U61254 \\
\hline Sporolithon durum [NZ Cable Bay South I] & EF628211 \\
\hline Sporolithale sp. [Rhodolith d'Urville I] & EF628212 \\
\hline \multicolumn{2}{|l|}{ Corallinales } \\
\hline \multicolumn{2}{|l|}{ Hapalidiaceae } \\
\hline \multicolumn{2}{|l|}{ Choreonematoideae } \\
\hline Choreonema thuretii & AY221254 \\
\hline \multicolumn{2}{|l|}{ Melobesioideae } \\
\hline Ciathromorphum compactum & U60742 \\
\hline Clathromorphum parcum & U61252 \\
\hline 'Leptophytum' acervatum & U62119 \\
\hline 'Leptophytum' ferox & U62120 \\
\hline Lithothamnion giaciale & U60738 \\
\hline Lithothamnion sp. BISH 689378 & DQ629010 \\
\hline Lithothamnion tophiforme & U60739 \\
\hline Mastophoropsis canaliculata & U62118 \\
\hline Melobesioideae sp. BISH 683176 & DQ628972 \\
\hline Mesophylium engeihartii [SAF] & U61256 \\
\hline Mesophyilum erubescens [Brazil] & U61257 \\
\hline Mesophyilum erubescens [NZ Chatham I] & EF628222 \\
\hline Mesophyllum erubescens [NZ Golden Bay 1] & EF628220 \\
\hline Mesophyilum erubescens [NZ Golden Bay 2] & EF628221 \\
\hline Mesophyllum erubescens [NZ Wellington] & EF628223 \\
\hline Mesophyllum erubescens [NZ Wharariki Beach] & EF628219 \\
\hline Mesophyllum printzicnum [NZ Chatham I] & EF628224 \\
\hline Mesophyilum sp. [NZ Chatham I] & EF628218 \\
\hline Phymatolithon laevigatum & U60740 \\
\hline Phymatolithon lenormandii & U60741 \\
\hline Phymatolithon repandum [NZ Kaikoura] & EF628216 \\
\hline Phymatolithon repandum [NZ Chatham I] & EF628215 \\
\hline Synarthrophyton schielianum & EF628217 \\
\hline \multicolumn{2}{|l|}{$\begin{array}{l}\text { Corallinaceae } \\
\text { Corallinoideae }\end{array}$} \\
\hline \\
\hline Arthrocardia carinata CH968 & EU095601 \\
\hline Arthrocardia filicula & U61258 \\
\hline Arthrocardia flabellata & EU095603 \\
\hline Arthrocardia sp. ASD200 [NZ Northland] & EF628230 \\
\hline Bossiella califormica ssp. schmittii & U60945 \\
\hline Bossiella orbigniana ssp. dichotoma & U60746 \\
\hline Bossiella orbigniana ssp. orbigniana & EU095604 \\
\hline Callarthron cheilosporioides & U60943 \\
\hline Calliarthron tuberculosum & U60944 \\
\hline Cheilosporum cultratum & EU095605 \\
\hline Cheilosporum sagittatum [AUS] & U60745 \\
\hline Cheilosporum sagittatum ASD165 [NZ Gisborne] & EF628226 \\
\hline Corallina elongata & U60946 \\
\hline Corallina elongata $\mathrm{CH} 989$ & EU095607 \\
\hline Corallina elongata IRV50 & FM180099 \\
\hline Corallina officinalis & L26184 \\
\hline Corallina officinails ASE091 [NZ Wellington] & EF628232 \\
\hline Coralilina officinaiis $\mathrm{CH} 507$ & EU095606 \\
\hline Corallina sp. 343a & FM180101 \\
\hline Haliptilon roseum [AUS] & U60947 \\
\hline Haliptilon roseum $\mathrm{CH} 750$ & EU095614 \\
\hline Hailiptilon roseum [NZ Stewart I 1 ASE0277] & EF628229 \\
\hline Hailiptilon roseum 0 К 244 & EU095609 \\
\hline Hailptilon sp. CH935 & EU095616 \\
\hline Haliptilon squamatum $\mathrm{CH} 985$ & EU095617 \\
\hline Jania adhaerens & EU095620 \\
\hline Jania crassa & U62113 \\
\hline Jania rubens & U61259 \\
\hline Jania sp. KC145 & EU095627 \\
\hline Jania sp. OK239 & EU095625 \\
\hline Jania ungulata & EU095627 \\
\hline Jania verrucosa $\mathrm{CH} 735$ & EU095628 \\
\hline Marginisporum declinata & EU095632 \\
\hline
\end{tabular}


Table 2 (continued)

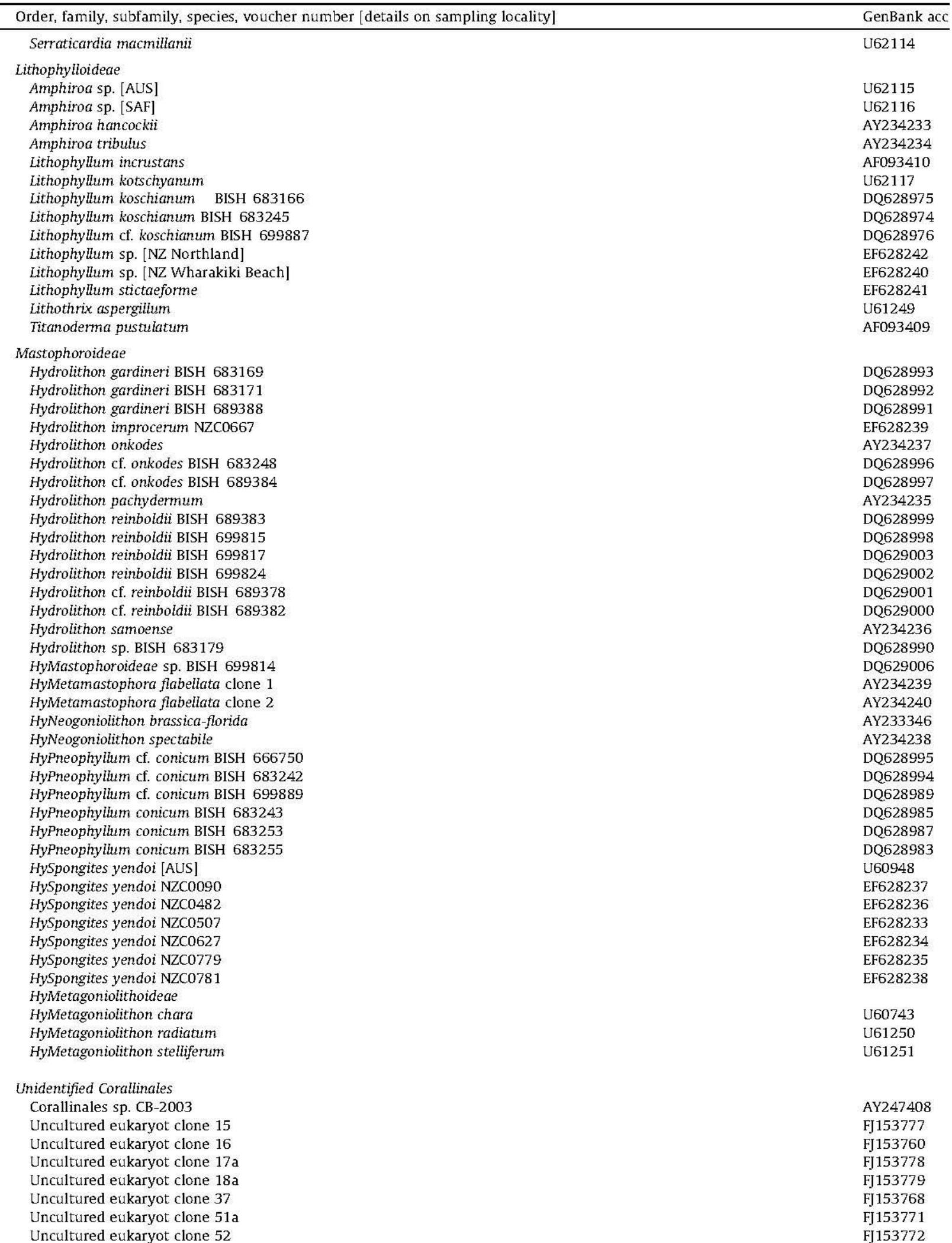




\subsection{Detection of long branches attraction (LBA)}

SlowFaster software (Kostka et al., 2008) was used to detect potential long branches attraction artifacts. SlowFaster was designed to: (i) assess the substitution rate of all the aligned positions assuming that some monophyletic groups are known a priori; (ii) identify slow and fast evolving sites; and (iii) create new alignments with different proportions of slow/fast evolving sites. Using an initial alignment and a tree topology (including nodes with constraint monophyly), SlowFaster counts the maximum number of changes in a position of the alignment. Once the largest number of changes per position is defined, SlowFaster partitions the dataset in new alignments. For instance, if the maximum number of changes per position in an alignment is four, SlowFaster will from the original dataset build four new alignments, labelled So, S1, S2 and S3. So alignment is the shortest one and contains no homopla- sic signal (no changes per position) within the admitted monophy- letic groups. S1 alignment is longer than So and includes all positions with at most one change in the admitted monophyletic groups, and so on for S2 and S3. Both datasets (one marker in data- set 1, four markers in dataset 2) were analysed with SlowFaster, and we assumed the monophyly of the Corallinales as the single constraint to build sub-datasets. Phylogenetic analyses of ML and BS support (of 2000 replicates) calculations were then performed on each of these sub-datasets with the same partitioning strategy and the same model of evolution than previously selected (see Section 2.4). Comparisons of the phylogenies and of the BS obtained with these subdatasets were then made to see if the results obtained with the initial alignments were influenced by fast evolving sites and potential LBA artifacts. Moreover, in order to test whether the loss of informative positions in the sub-datasets influenced the statistical support of the resulting tree topology, for each of the sub-datasets (for instance So-S3), alignments of same length, but comprising a random selection of positions (e.g. a random mix of fast and slow evolving sites), were prepared. Ten Jackknife datasets were then built for each sub-dataset using the Jackknife option of the SlowFaster and the same analyses (phylogenetic analyses of ML and BS calculations, with the same partitioning strategy and model of evolution than selected previously) were performed on each of these random shortened alignments.

\subsection{Ancestral state reconstructions}

Based on previous publications and on the examination of the histological sections of our specimens, a matrix of morphological and anatomical characters was built. The states of five features traditionally involved in the identification of coralline algal orders, families and subfamilies, were encoded (matrix is provided in Supp. Mat. 4). These included: (1) the absence or presence of genic- ula (genicula refer to the uncalcified joints that alternate with calcified segments of the thallus; the presence of genicula separates the articulated (geniculate) coralline algae from the crustose or non-geniculate corallines); (2) cell fusions common or not (cells of contiguous vegetative filaments may be joined secondarily by cell fusions that correspond to the 
break down of a part of the cellular wall and the melding of the cell content); (3) secondary pit- connections common or not (cells of contiguous filaments may be linked secondarily by pit-connection that correspond to an adjoining opening in the cell walls); (4) the absence or presence of uniporate or multiporate tetrasporangial conceptacles (Tetrasp- orangia are produced either in conceptacles where the roof may have a single pore (uniporate) or a number of pores (multiporate) through which spores are released, or are produced in sori that possess only a single pore); and (5) the absence or presence of tet- rasporangial pore plugs (within conceptacles/sori, individual tet- rasporangia may form an apical pore plug that occupies a space in the roof directly above the sporangium.

A consensus tree of the Corallinales (a cladogram) was drawn considering the major, well-resolved lineages (BS>85) recovered with the phylogenetic analyses of dataset 1 and 2 (Figs. 1 and 2). All characters were then encoded as discrete, unordered states, and their evolution was traced on the previously described Coral- linales tree using parsimony reconstruction implemented in Mes- quite version 2.6 (Maddison and Maddison, 2006).

\section{Results}

This study provided 258 new sequences deposited in GenBank (accession numbers are listed in Table 1): 63 sequences of SSU, 63 sequences of LSU, 62 sequences of $\mathrm{COI}$ and 70 sequences of $p s b \mathrm{~A}$. A noticeable low percentage of missing data in the concatenated dataset can be pointed out. In dataset 2, only $4 \%$ of the sequences were missing. Phylograms resulting from the ML analyses are presented in Fig. 1 for dataset 1 and in Fig. 2 for data- set 2. Lineages were named with letters (A to V) to facilitate the reading of the following sections. In Fig. 1, lineages B, N, U are not recovered. In Fig. 2, lineages D, I, J, K R only include one taxon, and the lineage H is not represented in dataset 2 . The average number of statistically well-resolved nodes and details of statistical support of the lineages A to $U$ is reported for each topology (Figs. 1 and 2) and for each analyse in Supp. Mat. 5A and 5 B.

\subsection{Phylogenetic signal of the two datasets 3.1.1 Basic metrics}

Dataset 1 (191 taxa and 1549 base pairs (bp)) included 1068 constant characters (CC) and 341 parsimony-informative characters (PI). Dataset 2 (70 taxa and $5503 \mathrm{bp}$ ) included $3837 \mathrm{CC}$ and $1390 \mathrm{PI}$. The contribution of each loci of dataset 2 was as follows: 1549 bp of SSU (CC = 1186, PI = 273), 2502 bp of LSU $(\mathrm{CC}=1816, \mathrm{PI}=547)$, $645 \mathrm{bp}$ of $\mathrm{COI}(\mathrm{CC}=336, \mathrm{PI}=285)$ and $807 \mathrm{bp}$ of $p s b A(\mathrm{CC}=499, \mathrm{PI}=285)$. The ratio PI vs. sequence length calculated for the dataset 2, clearly showed that the SSU was the least variable marker with the ratio of 0.17 followed by LSU (ratio $=0.22$ ) and then $p s b A$ (ratio $=0.35$ ); the marker containing the most PI was COI (ratio = $0.44)$. 


\subsubsection{Phylogenetic resolution}

BS was compared for several datasets (Supp. Mat. 5A). Dataset 1 had the advantage of covering a large diversity of coralline species, but rose only $30.7 \%$ of well resolved nodes (i.e. BS p 80, Supp. Mat. 5A) in the whole phylogenetic tree. In contrast, the tree resulting from the ML analysis of the gene-rich, but "taxa-poor" dataset (dataset 2) had nearly $73 \%$ of its nodes well resolved (Supp. Mat. 5A). Analyses of single loci included in dataset 2 clearly showed that LSU trees were more resolved than trees obtained with the other single marker. Deep phylogenetic relationships (lineages B, E, G, U; Supp. Mat. 5B) were better resolved by nuclear markers (SSU and LSU) than organelle genes. Recent nodes (corresponding to generic or species level) benefited both from the organellar ( $p s b A$ and COI) and the nuclear genetic information (Supp. Mat. 5B).

\subsubsection{SlowFaster analyses}

Assuming the monophyly of the Corallinales, the maximum number of observed changes in a position of the alignments was four for each dataset (dataset 1, and the four loci of the dataset 2). Thus, four new alignments were created. These subdatasets were labelled So up to S3, and contained gradually from So to S3 more saturated positions. So was the shortest alignment and contained only slow evolving sites. S3 was the longest alignment and contained the highest number of fast evolving sites (compared to So, S1 and S2); S1 and S2 were intermediate. Comparisons of BS evolution showed a similar trend with all datasets. So alignments contained no information (except the monophyly of the Coralli- nales). 


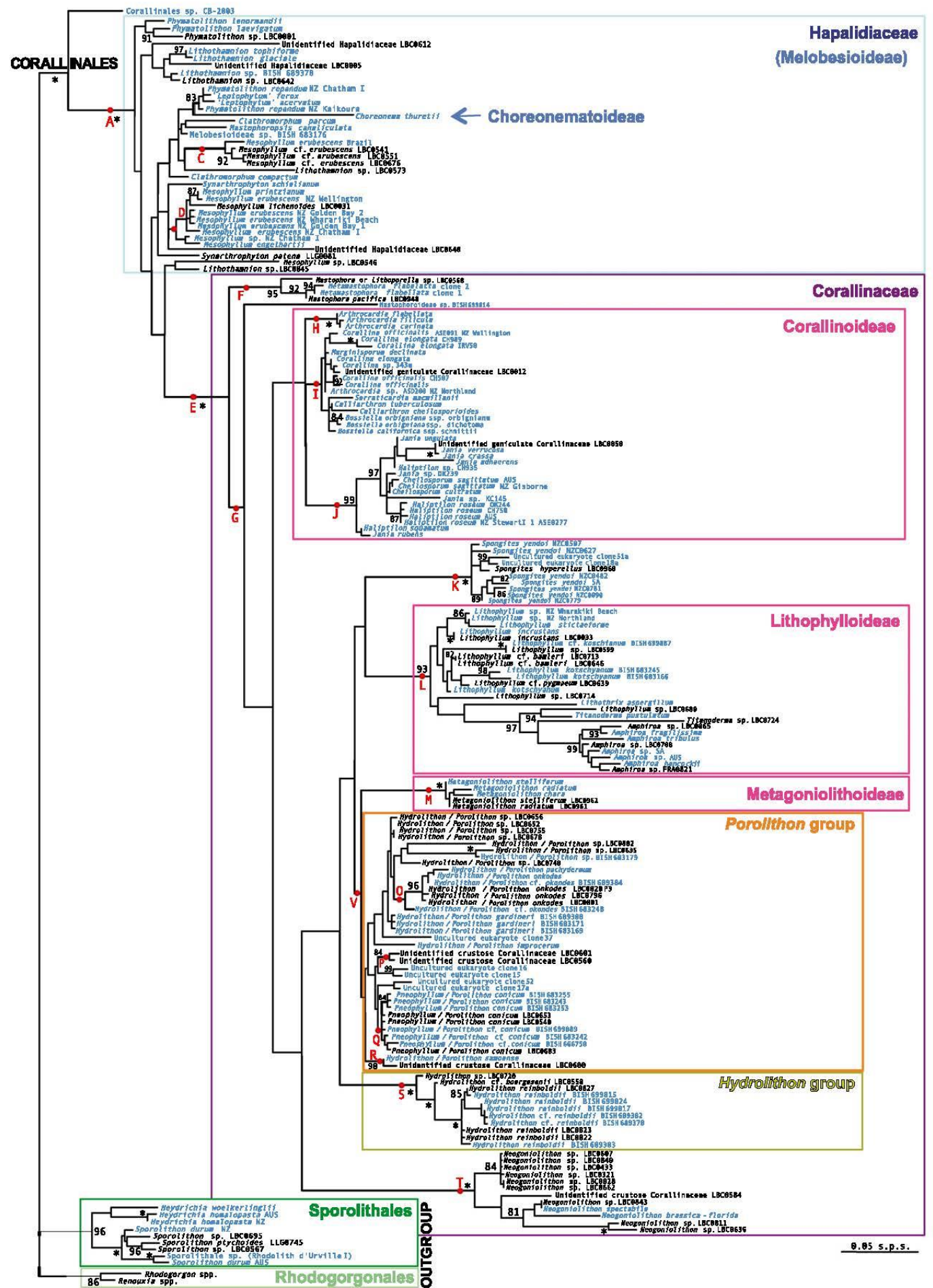

Fig. 1. Phylogram inferred from ML analyses with dataset 1 (SSU sequences, 1549 bp, 192 taxa). s.p.s. means number of substitutions per site. Sequences coloured in blue have been downloaded from GenBank. Values above or below nodes indicate BS (for 1000 replicates): * indicates BS of 100 . BS $<80$ are not indicated. Information on voucher number or / and on sampling area have been added in the specimens names in order to help to distinguish them when they shared the same species name (See list of specimens in Tables 1 and 2 . 


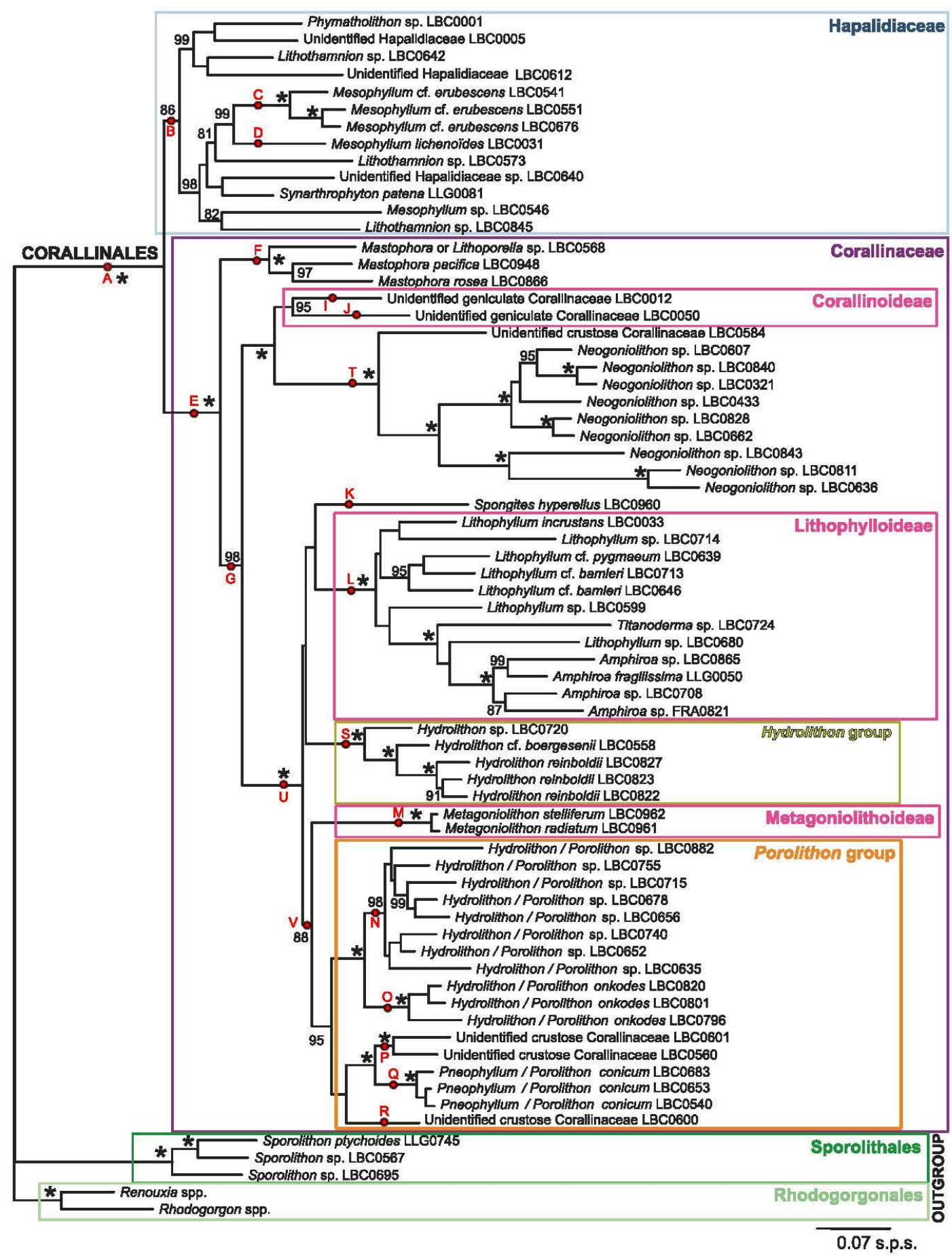

Fig. 2. Phylogram inferred from ML analyses with dataset 2 ( 4 genes sequences, $5503 \mathrm{bp}, 70$ taxa). s.p.s. means number of substitutions per site. Values above or below nodes indicate BS (for 1000 replicates): * indicates BS of 100 . BS $<80$ are not indicated. Information on voucher number or / and on sampling area have been added in the specimens names in order to help to distinguish them when they shared the same species name (See list of specimens in Table 2.).

S1 hardly resolved a few nodes (except for the LSU) and BS increased suddenly with the alignment of S2 (Supp. Mat. 5B). The highest BS were obtained with either the initial alignments (for the majority of the pointed out nodes), or with the $\mathrm{S} 3$ alignments (Supp. Mat. 5B). The only group that behaved slightly differently was the 
lineage $(\mathrm{N}+\mathrm{O}+\mathrm{P}+\mathrm{Q}+\mathrm{R})$ in dataset 2, which had a higher BS with the dataset $\mathrm{LSU}$ - S3 or S2. This lineage was nevertheless also strongly supported in the concatenated analyses of dataset $2(\mathrm{BS}=88)$.

Jackknife datasets of the same length as the two informative datasets (S2, $\left.\mathrm{S}_{3}\right)$, but shortened by random deletion of positions, were also analysed for dataset 1 and for each partition of dataset 2. Ten of these randomly shortened datasets were analysed (20 alignments per locus, in total: 100 analyses). The average of the BS obtained with the Jackknifed datasets was always lower than the BS found with S2 and S3 sets (details of the analyses not provided here).

Finally, the SlowFaster analyses suggested that in our datasets BS increased with the length of the alignment analysed. BS was thus not due to phylogenetic noise.

\subsection{Phylogenetic inferences resolved relationships}

\subsubsection{Among the Corallinales}

Phylogenies inferred from dataset 1 and 2 recovered with full support the monophyly of the Corallinaceae (Figs. 1 and 2). In contrast, the Hapalidiaceae (node B) was resolved as a monophyletic lineage only when the multi-marker dataset was analysed (BS = 86, Fig. 2). Single locus analyses (Supp. Mat. 5) seldom resolved the Hapalidiaceae as monophyletic whereas the Corallina- ceae (node E) form a strongly supported monophyletic lineage in phylogenies inferred from nuclear markers (Supp. Mat. 5B).

\subsubsection{Within the Hapalidiaceae}

Our analyses included representatives of the Melobesioideae and

Choreonematoideae (represented by a single monospecific genus), two of the three subfamilies currently recognised in the Hapalidiaceae. The only member of the Choreonematoideae, Cho- reonema thuretii (Bornet) F. Schmitz, was resolved as a long branch with low support for its position within the Hapalidiaceae (Fig. 1). Dataset 1 included twelve different sequences of specimens identified as Mesophyllum erubescens from various locations (nine from GenBank and three generated in the present study), which were resolved within two distant and unrelated lineages (node $\mathrm{C}$ and D). Specimens from the Melanesian region (Vanuatu, Fiji) allied with one specimen from the type locality (Brazil) of the species. All specimens from New Zealand were resolved along with other congeneric species within the lineage D. The specimens from Wellington (New Zealand) joined Mesophyllum printzianum and together they were resolved as the sister lineage of Mesophyllum lichenoides

\subsubsection{Within the Corallinaceae}

Lithophylloideae and Metagoniolithoideae (lineages L and M, respectively) were recovered as monophyletic lineages with strong support (Supp. Mat. 5B, Figs. 1 and 2). Corallinoideae (lineages $\mathrm{I}+\mathrm{J}+\mathrm{H}$ ) were also resolved as monophyletic with both 
datasets (Figs. 1 and 2). However, only the multi-markers dataset strongly supported the monophyly of the Corallinoideae $(\mathrm{BS}($ dataset 1$)=69$, BS(dataset 2) $=95)$. Within the lineage I, three specimens identified as Corallina officinalis and three specimens identified as Corallina elongata displayed distinct SSU sequences and phylogenetic analyses split these two species into several distinct lineages (Fig. 1).

In our multi-marker analyses members of the subfamily Masto- phoroideae were resolved into four distinct strongly supported lineages (nodes F, K, T, N + O + P + Q+ $\mathrm{R}$ ) (Fig. 2). Analyses of both datasets resolved the lineage $\mathrm{F}$ as the earliest divergence within the Corallinaceae and encompassed species of Mastophora, Metamastophora and possibly Lithoporella (Figs. 1 and 2). Species of Neo-goniolithon included in both datasets clustered together with the unidentified specimen LBCo584 within the lineage $\mathrm{T}$ despite their high genetic divergence. Species of the genus Spongites were resolved as the sister lineage (node K) to the Lithophylloideae in both analyses albeit without statistical support. Analyses of both data- sets recovered species of Pneophyllum as a monophyletic lineage (node Q), which allied with full support in combined loci analyses with unidentified specimens (nodes $\mathrm{P}$ and $\mathrm{R}$ ) forming altogether the sister taxa of Hydrolithon onkodes (node $\mathrm{O}$ ), and an unidentified species of Hydrolithon (node N). The lineages N, O, P, Q and R clustered with the Metagoniolithoideae (lineage $\mathrm{M}$ ) with high support (lineage labelled V, $\mathrm{BS}=88$, dataset 2). The remaining representatives of the genus Hydrolithon (Hydrolithon reinboldii, Hydrolithon cf. boergesenii and Hydrolithon sp. (LBCO720)), allied together and formed the lineage $\mathrm{S}$, which phylogenetic position was unclear within the lineage $\mathrm{U}$.

Several specimens included in dataset 1 were annotated on GenBank as 'uncultured eukaryotes' (Medina-Pons et al., 2009). On Fig. 1, some of them were resolved among members of Spong- ites and others as relatives to Pneophyllum and Hydrolithon species characterized by a dimerous thallus structure.

\subsection{Ancestral states reconstruction}

Ancestral state reconstructions have been performed for five morpho-anatomical characters (Fig. 3). Combinations of these character states are traditionally used to identify families and subfamilies in the Corallinales (details in Supp. Mat. 1). Parsimony reconstructions of the evolution of these characters highlight a high degree of homoplasy of these features. The first feature (i.e. absence or presence of uniporate or multiporate tetrasporangial conceptacles) is the only one useful as a diagnostic character. Each character state associated with this feature corresponds to a family. The Hapalidiaceae possess multiporate tetrasporangial con- ceptacles, whereas the Corallinaceae possess uniporate tetraspo- rangial conceptacles. The second feature shows the presence of tetrasporangial pore plugs in both Sporolithales and Hapalidiaceae. It is, however, not possible to infer if pore plugs in these two lineages were derived from a common ancestor. Cell fusions are common (feature 3 ) in 
the Corallinales except in Lithophylloideae (Lineage L), and have also been described for taxa from the out- group Rhodogorgonales. Further developmental studies are thus required to evaluate whether this character state is autapomorphic to the Lithophylloideae. The predominance or frequent presence of secondary pitconnections (feature 4) and the presence of genicula (feature 5) occur several times in the corallinalean tree. In the majority of the Corallinales secondary pitconnections are absent or rare; the subfamily Lithophylloideae and some species from the Mastophoroid genus Metamastophora are exceptions. Similarly, genicula appear at least four times in the corallinean tree (twice in lineage L). All the features and their character states appear to have evolved independently from each other.

\section{Discussion}

\subsection{Improvement of phylogenetic resolution within the Corallinales}

Simulation studies have established that the accuracy of phylo- genetic trees determined from molecular data can be improved by adding more taxa and more markers (Rokas and Carroll, 2005).

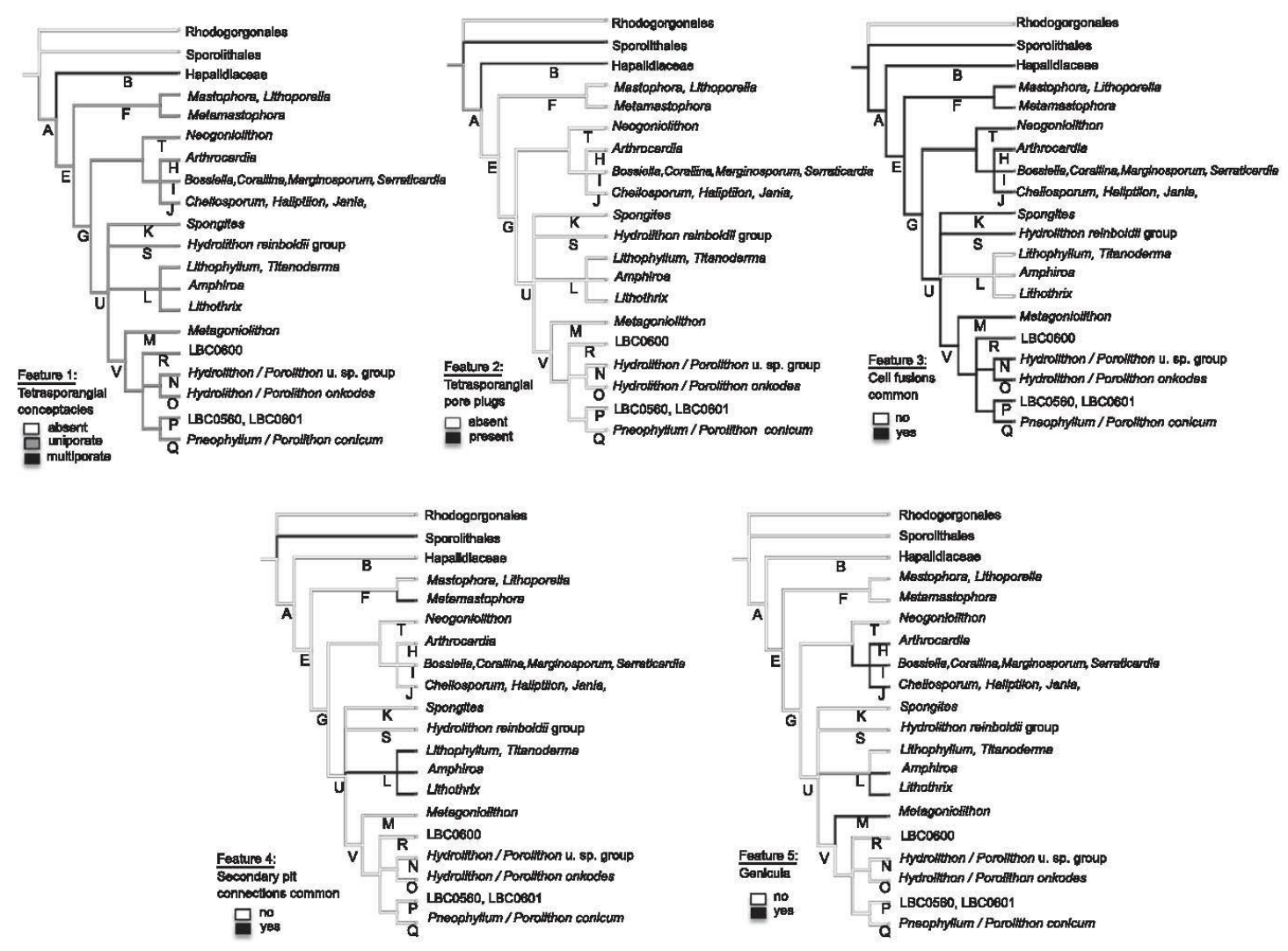

Fig. 3. Mapping of morpho-anatomical characters classically employed to describe the Corallinales families and subfamilies (Supp. Mat. 1). A combination topology for main lineages from Figs. 1 and 2 has been made, and character states (see Supp. Mat. 4) were mapped onto this Corallinales phylogeny. Ancestral states were inferred under a parsimony criterion with Mesquite version 2.6 (Maddison and Maddison, 2006). Character states encoding is provided as legend next to each tree u. sp. means unidentified species. 
Phylogenetic relationships inferred from our combined loci analyses are largely congruent with those inferred from SSU published by Bailey et al. (2004). Moreover, in the present study these relationships are statistically more strongly supported, suggesting that the incorporation of many taxa and addition of new molecular markers greatly improved the resolution of phylogenetic relationships within the Corallinophycidae. LSU sequences in particular contributed to improve the resolution of phylogenetic relationships observed when analyses where performed using the multi- marker dataset (Supp. Mat. 4, Fig. 2). This was likely due to its length (here $2502 \mathrm{bp}$ ) as well as its phylogenetic signal. In a recent study Broom et al. (2008) stated that $p s b \mathrm{~A}$ has considerable potential as a marker for the Corallinales because it is easily amplified and considerably more variable than SSU. COI is another gene that has recently been used to assess subfamilial relationships within the Corallinales (Walker et al., 2009) and this marker, selected as the DNA-barcode for the Rhodophyta, is currently widely se- quenced by the barcode community to populate the Barcode Of Life Database (Ratnasingham and Hebert, 2007). Nevertheless, our analysis of the proportion of nodes with high bootstrap for each marker show that LSU is significantly more informative than the other markers. This is followed by psbA and then COI and SSU. This result confirmed empirically that LSU is an efficient marker to assess phylogenetic relationships within the Corallinales at several taxonomic levels. Within the Rhodophyta several studies (e.g. Harper and Saunders, 2001b, 2002; Saunders and Lehmkuhl, 2005; Le Gall and Saunders, 2007; Le Gall et al., 2008) have highlighted that LSU provide good resolution at both deep and terminal nodes. We therefore recommend that LSU, rather than SSU sequences, be used to pursue further phylogenetic inferences within the Corallinales. However, considering that $p s b$ A sequences (1) are easy to amplify, (2) only require two sequencing reactions (one forward, one reverse), (3) can be aligned unambiguously and (4) provide significant phylogenetic signal in recent and deep branching (Broom et al., 2008), focusing on the use of new plastid- ial sequences other than LSU sequences, might also be an attractive strategy to access coralline algal relationships in future analyses. The studies of sub-datasets (built with the SlowFaster software, Kostka et al., 2008), where fast-evolving sites were removed, showed that our alignments were not affected by phylogenetic noise. It seems therefore likely that our trees are not suffering from long branches attraction.

\subsection{Suprageneric relationships among the Corallinales}

Our phylogenies confirm the monophyly of the coralline algal families Corallinaceae and Hapalidiaceae, as well as most of their subfamilies as delineated by Harvey et al. (2003).

\subsubsection{Hapalidiaceae}

When analyses were performed with the multi-marker dataset, the Hapalidiaceae (node B) were well supported $(\mathrm{BS}=86$ ) in comparison to the few previous studies that also recovered this lineage as monophyletic (Bailey and Chapman, 1998 [as the 
Melobesioi- deae: BS (with a Maximum of Parsimony analyse, MP) $=61$ ], Harvey et al., 2003 [BS(ML) $<50$ and BS(MP) = 64]). Broom et al. (2008) only found the monophyly of Hapalidiaceae with their worldwide dataset based on SSU sequences (BS(Neighbour-Joining analyse) $=99, \mathrm{BS}(\mathrm{ML})=91$, Posterior probabilities for Bayesian analyses $=1.00$ ). In Fig. 1, the phylogetenic tree shows an outgroup situated on a long ingroup branch and an ingroup constituted from a highly unequal root-totip path lengths with a comb-like structure (branch lengths are slightly shorter near the base and are then increasingly longer moving through the Hapalidiaceae towards the Corallinaceae). This distinct structure suggests that the paraphyly of the Hapalidiaceae from the SSU dataset may not be a true biological pattern: it could have resulted from a methodological bias (Shavit et al., 2007). Nevertheless, SlowFaster analyses (Kostka et al., 2008) show that alignments (from datasets 1 and 2) did not appear to be affected by phylogenetic noise. The monophyly of the Hapalidiaceae is in fact mainly due to the phylogenetic signal of the LSU marker. The Hapalidiaceae as delineated by Harvey et al. (2003) based on morphological and anatomical characters (zonately arranged tetra/bisporangia born in multiporate concep- tacles that bear apical pore plugs) is therefore supported to form a natural lineage within the Corallinales. However, our multi-marker analyses only included members of the Melobesioideae; representatives from the other two subfamilies (Austrolithoideae and Choreonematoideae) should be included in future multimarker studies to strengthen these results (as to date only one SSU sequence from $C$. thuretii is available). The latter two subfamilies are poorly known and respectively include three and one mono- specific genera that are mostly endophytic or parasitic on genicu- late species from the Corallinaceae subfamily, Corallinoideae (Townsend and Huisman, 2004).

\subsubsection{Corallinaceae: a revision from the subfamilies boundaries}

An updated taxonomic scheme (Fig. 4) of the Corallinaceae is presented based on the phylogenetic relationships inferred from our datasets.

Emendation of the Mastophoroideae. Within the fully supported lineage corresponding to the Corallinaceae (node E), three of the four subfamilies namely the Corallinoideae (nodes H $+\mathrm{I}+\mathrm{J}$ ), Lithophyl- loideae (node $\mathrm{L}$ ) and Metagoniolithoideae (node M) were resolved as monophyletic. However, the fourth subfamily, the Mastophoroi- deae was resolved as several independent lineages. This result is consistent with the phylogenies inferred by Bailey et al. (2004) who first highlighted the polyphyly of this subfamily. Unfortunately, their dataset did not include any representatives of the type genus Mastophora preventing them from proposing a revision to this subfamily. Our analyses, which included several species of Mastophora, including the type species M. rosea (Figs. 1 and2)(Setchell, 1943), resolved this genus as a sister group to the genera Lithoporella and Metamastophora within a lineage sister to the remaining Corallina- ceae. Based on the phylogenetic position of Mastophora, we propose to restrict the subfamily Mastophoroideae to 
only the genera Litho- porella, Mastophora and Metamastophora (Lineage F, Figs. 1 and 2). As emended here, Mastophoroideae includes taxa of the Corallinaceae with a ventral or central layer of predominantly palisade cells throughout the thallus. This character has already been used by Woelkerling (1988) to distinguish Mastophora from other genera within the subfamily Mastophoroideae sensu lato.

Affinities within the lineage $G$ Lineages $\mathrm{H}$, I and $\mathrm{J}$ correspond to the Corallinoideae sensu (J.E. Areschoug) Foslie and are restricted to geniculate genera. In the combined analyses, they are resolved as the sister group to lineage $\mathrm{T}$, which encompasses taxa from the genus Neogoniolithon. These data corroborate Bailey et al.'s (2004) results and support Cabioch's $(1972,1988)$ assessment that

Neogoniolithon is more closely related to the Corallinoideae than to other nongeniculate groups.

Neogoniolithon fosliei (Heydrich) Setchell \& L.R. Mason, the type species of the genus Neogoniolithon is regarded as an heterotypic synonym of Neogoniolithon brassica-florida (Harvey) Setchell et Mason (Woelkerling et al., 1993b). Numerous taxa including Neogon- iolithon frutescens and Neogoniolithon laccadivicum have been transferred to N. brassica-florida (Guiry and Guiry, 2011). However, Kato et al. (2009) refined the delineation of $N$. brassica-florida using molecular data (SSU) and concluded that the circumscription of the species based on Verheij (1994) is not appropriate. The crustose and fruticose specimens analysed in their study and referred to $N$. fosliei and $N$. frutescens respectively formed several distinct clades, a result which is usually considered to reflect different species. In our dataset, several distinct clades correspond to Neogoni- olithon crusts with large conceptacles assigned to the complex $N$. fosliei/brassica-florida. Thorough morphological studies are thus required to better delineate this complex and supplementary phylo- genetic analyses have to be performed to unravel the true taxonomic affinities of all the species currently recognised within the genus Neogoniolithon.

Neogoniolithon and Corallinoideae specimens share common reproductive features namely: (1) the position of the spermatangia on the floor, walls and roof of the male conceptacles; (2) the distribution of gonimoblast filaments across the dorsal surface of the fusion cell; and (3) the similar peripheral development of the tetrasporangial conceptacle roofs in both lineages. This later character, however, is also observed in the Mastophoroideae sensu lato genera Spongites, Lesueria, Mastophora and Metamastophora, and so it is not diagnostic for the lineage $(\mathrm{H}+\mathrm{I}+\mathrm{J}+\mathrm{T})$. Nevertheless the first two characters differ from all other mastophoroids and can thus be used to distinguish members of this lineage $(\mathrm{H}+\mathrm{I}+\mathrm{J}+\mathrm{T})$ from others in the lineage G. Bailey et al. (2004) had suggested transferring the genus Neogoniolithon from the Mastophoroideae to the Corallinoideae. In light of the current findings, a global revision of the taxonomy and a re-defining of the ranks of the classification within the Corallinaceae have to be undertaken. 
The lineage U, which comprises the Lithophylloideae, Metago- niolithoideae and the remaining genera of the Mastophoroideae sensu lato (Spongites, Hydrolithon, Pneophyllum) is strongly supported in our multi-markers dataset. This grouping was previously shown by Bailey (1999) and Bailey et al. (2004), but was not well supported. Similarly, in the current study, inter-group relationships within the lineage U remain poorly resolved.

The affinity of the genus Spongites (lineage K) needs to be confirmed by studying the generitype Spongites fructiculosus (Kutzing), a species unfortunately not included in our datasets. The lineage (L) corresponds to the Lithophylloideae sensu Cabioch (1972). It includes the type genus and species Lithophyllum incrustans, and encompasses both geniculate (Amphiroa and Lithothrix only in dataset 1) and nongeniculate (Lithophyllum/Titanoderma) genera. These results are consistent with Bailey's (1999) work. The Litho- phylloideae are characterized by the predominance of secondary pit-connections between cells of contiguous filament with cell fusions being absent or comparatively rare. Surprisingly, our results failed to resolve the controversial taxonomic status of the genus Titanoderma. The limited molecular evidence available favours placing the type species of Lithophyllum and Titanoderma in separate genera (Bailey, 1999; present study). The morphological criteria proposed to separate the two genera (basal layer of palisade cells and bistratose margins $v s$. basal layer of non-palisade cells and non-bistratose margins for Titanoderma vs. Lithophyllum respectively), however, do not stand up to rigorous testing because all these characters can occur together in the same thallus to varying degrees (Campbell and Woelkerling, 1990; Woelkerling and Campbell, 1992). Thus it is impossible to draw meaningful, reliable generic boundaries on the morphological grounds currently proposed as the material studied here had the Titanoderma-type diagnostic characters (namely a basal layer of palisade cells and bistratose margins), but did not join the generitype Titanoderma pustulatum. More morphological, anatomical and molecular analyses are thus needed to better circumscribe these two taxa (Litho- phyllum/Titanoderma). 
Maneveldt (2005), we propose to resurrect the genus Porolithon for those species displaying a primarily mono- merous thallus construction and possessing trichocytes in large horizontal, pustulate (as "pustulous" byAdey, 1970) fields without any normal vegetative filaments between the individual tricho- cytes. Accordingly, we also propose to re-assign Hydrolithon craspe- dium, (Foslie) P.C. Silva Hydrolithon gardineri (Foslie) Verheij \& Prud'homme van Reine, Hydrolithon improcerum (Foslie \& M.A. Howe) Foslie, Hydrolithon munitum (Foslie \& M.A. Howe) Penrose, Hydrolithon pachydermum (Foslie) J.C. Bailey, J.E. Gabel, \& D.W. Freshwater, Hydrolithon samoense (Foslie) Keats \& Y.M. Chamberlain, Hydrolithon superficiale Keats \& Y.M. Chamberlain and Hydroli- thon rupestris (Foslie) Penrose to the genus Porolithon (Maneveldt, 2005).

The status of Pneophyllum conicum (E.Y. Dawson) Keats, Y.M. Chamberlain \& Baba and its relationships with the genera Hydroli- thon and Porolithon also needs to be reconsidered. Hydrolithon conicum E.Y. Dawson was transferred to Pneophyllum by Keats et al. (1997) because the species has the tetrasporangial concepta- cle roof development said to be diagnostic of the genus Pneophyl- lum. However, Pneophyllum conicum (lineage Q) and presently several unidentified crustose specimens (LBC0601, LBC0560, lineage P; LBCo60o, lineage R) ally with the genus Porolithon (lineages $\mathrm{N}+\mathrm{O}$ ). Incidentally, these specimens also have a monomerous thallus organisation. We propose to also attribute these latter taxa to the genus Porolithon and suggest transferring Pn. conicum to Porolithon conicum comb. nov. In future studies, it would be worthwhile including other Pneophyllum species (and particularly the type species Pneophyllum fragile Kutzing), which all possess a dimerous thallus construction, to ascertain the phylogenetic position of this genus. It is also worth mentioning that Cabioch (1972) highlighted the similarity of the thallus development between the genus Metagoniolithon Weber-van Bosse and branched (protuberant) species of Porolithon.

Finally, our molecular data shows that the large lineage U, which is well supported, comprises five distinct evolutionarily lineages. Significant taxonomic changes at subfamily and lower ranks are clearly in need. This has to be addressed in future studies with exhaustive nomenclatural investigation.

Cryptic diversity in the Corallinales

The Corallinales are reported to be the third most diverse order within the Rhodophyta with 564 (Brodie and Zuccarello, 2007) to 601 (Guiry and Guiry, 2011) morpho-species currently recognized. Several taxa are supposedly cosmopolitan. However, their diversity has not been evaluated in light of molecular data.

Our phylogenies show clearly that re-appraisals of the genera Neogoniolithon as well as Mesophyllum (particularly M. erubescens) are necessary. The type species of 
Mesophyllum is M. lichenoides (Woelkerling and Irvine, 1986, 2007). While this species is included in our analyses, our species-rich dataset (Fig. 1) shows that specimens of $M$. erubescens from New Zealand are more closely related to $M$. lichenoides (lineage D) from France (Channel Sea) than to specimens of $M$. erubescens from the type-locality (Brazil), or from the South-Pacific Ocean (Vanuatu, Fiji) (lineage C). Broom et al. (2008) already highlighted the cryptic diversity of $M$. erubes- cens and our results confirm that this morpho-species has been overlooked. These findings thus warrant a thorough study of the species from various geographical locations combining morpho- anatomic observations and molecular phylogenies (inferred from a more variable marker than the SSU) to better delineate species frontiers within this complex.

\subsection{Considerations concerning diagnostic characters}

Mapping of the character states that are traditionally used to identify families and subfamilies in the Corallinales shows that, except for the absence or presence of uniporate or multiporate tet- rasporangial conceptacles, none are diagnostic and useful to define lineages at an infra-ordinal rank. Since sexual reproductive structures are rarely observable (Woelkerling, 1988), efforts should focus on finding additional vegetative structures, for example, trichocyte arrangements and presence of megacells are character states that have to be re-investigated. We advocate also that detailed studies of developmental features (as thallus ontogeny) can certainly shed new light into the evolutionary story of the numerous lineages within the Corallinales, as predicted by Cabioch $(1972,1988)$ a few decades ago.

\section{Conclusion and prospective studies}

This study used four molecular markers and included numerous representative taxa from all but one (Austrolithoideae) subfamily within the Corallinales, rendering it, to the best of our knowledge, the most comprehensive study of its kind to date. Our study shows that multi-marker analyses improves the resolution of the Corallinales phylogeny and that LSU and $p s b A$ sequences provide a better phylogenetic resolution than SSU, the most commonly used marker for Corallinales phylogeny. Amplification and sequencing of supplementary plastidial markers, or of nuclear encoding markers (such as EF2) would likely bring additional signal to clarify the phylogenetic relationships within the lineage $U$ of the Corallinaceae, which includes representatives of the genera Amphiroa, Hydrolithon, Litho- phyllum, Metagoniolithon, Pneophyllum, Spongites and Titanoderma.

In order to render the taxonomy of the Corallinales closer to a natural system of classification, new taxonomic delineations within the Corallinaceae (as the emendation of the Mastophoroideae only to the genera Lithoporella, Mastophora and Metamastophora) and the resurrection of the genus Porolithon are proposed. Despite our well-resolved and taxon-rich dataset, phylogenetic affinities of many 
coralline algal taxa still need to be addressed. The genera Lithothamnion and Lithophyllum, which encompass 80 and 112 species respectively (Guiry and Guiry, 2011), should be studied in further detail to better delineate taxon boundaries. Efforts should also be made toward including more 'rare' species such as the monospecific taxa Lesueuria minderiana Woelkerling \& Ducker (described as a Mastophoroideae, Woelkerling and Ducker, 1987) and Boreoli- thon van-heurckii (Heydrich) A.S. Harvey \& Woelkerling, as well as various parasitic forms (as listed in Townsend and Huisman, 2004).

Finally, Corallinales show an extensive and robust fossils records because of the calcification of their cell walls (Aguirre et al., 2010). However some specimens, because of the poor preservation and/or absence of diagnostic morpho-anatomical characters, cannot be pinpointed easily to current living clades. Next challenges will certainly be to produce and then include sequences from fossils for comparison against extant lineages (Hughey et al., 2008). The present study provides a reliable phylogeny which, coupled with few strong reliable calibration points inferred from the fossil record, could be used to improve molecular clock analyses within the Corallinales. To date, splitting events were inferred without representatives of the Mastophoroideae due to the suspected paraphyly of this subfamily (Aguirre et al., 2010). The molecular data set that we have provided in the present article will most likely contribute to understanding evolutionary scenarios on the diversification (speciation/extinction), colonisation, and recurrent morpho-anatomical convergence events within the coralline algae, as well as the calibration of the red algal tree of life.

\section{Acknowledgments}

LB is a doctoral fellow of the French MENRT. This work was supported by the 'Service de Systematique Moleculaire of the Museum National d'Histoire Naturelle (UMS2700), the Consortium National de Recherche en Genomique on the project Macrophylogeny of life directed by G. Lecointre, and the ANR BIONEOCAL granted to P. Grancolas. LB is grateful to the IRD Noumea diving team: F. Leliaert, O. De Clerck, S.GA. Draisma, P. Mitrovski, A. Harvey, F. Rousseau and T. Silberfeld for collecting specimens. Phylogenetic analyses were performed on the CIPRES (Cyberinfrastructure for Phylogenetic Research) portal. GWM acknowledges research support from the South African National Research Foundation. The authors gratefully thank two anonymous referees for their thorough reviews and constructive criticism on a previous version of the manuscript.

\section{Appendix A. Supplementary material}

Supplementary data associated with this article can be found, in the online version, at doi:10.1016/j.ympev.2011.07.019. 


\section{References}

Adey, W.H., 1970. A revision of the Foslie crustose coralline herbarium. Det K. Nor. Vidensk. Selsk. Skr. 1, 1-46.

Aguirre, J., Perfectti, F., Braga, J.C., 2010. Integrating phylogeny, molecular clocks, and the fossil record in the evolution of coralline algae (Corallinales and Sporolithales, Rhodophyta). Paleobiology 36, 519-533.

Akaike, H., 1973. Information theory and an extension of the maximum likelihood principle. In: Petrov, B.N., Csaki, F., (Eds), Second International Symposium on Information Theory. Akademiai Kiado, Budapest, Hungary, pp. 267-281.

Amado-Filho, G.M., Maneveldt, G., Manso, R.C.C., Marins-Rosa, B.V., Pacheco, M.R., Guimaraes, S.M.P.B., 2007. Structure of rhodolith beds from 4 to 55 meters deep along the southern coast of Espfrito Santo State, Brazil. Cienc. Mar. 33, 399410.

Bailey, J.C., 1999. Phylogenetic positions of Lithophyllum incrustans and Titanoderma pustulatum (Corallinaceae, Rhodophyta) based on 18S rRNA gene sequence analyses, with a revised classification of the Lithophylloideae. Phycologia 38, 208-216.

Bailey, J.C., Chapman, R.L., 1996. Evolutionary relationships among coralline red algae (Corallinaceae, Rhodophyta) inferred from 18S rRNA gene sequence analysis. In: Chaudhary, B.R., Agrawal, S.B. (Eds.), Cytology, Genetics and Molecular Biology of Algae. SPB Academic Publishing, Amsterdam, pp. 363-376.

Bailey, J.C., Chapman, R.L., 1998. A phylogenetic study of the Corallinales (Rhodophyta) based on nuclear small-subunit rRNA gene sequences. J. Phycol. 34, 692-705.

Bailey, J.C., Gabel, J.E., Freshwater, D.W., 2004. Nuclear 18S rRNA gene sequence analyses indicate that the Mastophoroideae (Corallinaceae, Rhodophyta) is a polyphyletic taxon. Phycologia 43, 3-12.

Bittner, L., Halary, S., Payri, C., Cruaud, C., de Reviers, B., Lopez, P., Bapteste, E., 2010. Some considerations for analyzing biodiversity using integrative metagenomics and gene networks. Biol. Direct 5, 47.

Broadwater, S.T., Harvey, A.S., Lapointe, E.A., Woelkerling, W.J., 2002. Conceptacle structure of the parasitic coralline red alga Choreonema thuretii (Corallinales) and its taxonomic implications. J. Phycol. 38,1157-1168. 
Brodie, J., Zuccarello, G.C., 2007. Systematics of the species rich algae: red algal classification, phylogeny and speciation. In: Hodkinson, T.R. (Ed.), Reconstructing the Tree of Life: Taxonomy and Systematics of Species Rich Taxa. CRC/Taylor and Francis, Boca Raton, Florida, pp. 317-330.

Broom, J.E.S., Hart, D.R., Farr, T.J., Nelson, W.A., Neill, K.F., Harvey, A.S., Woelkerling, W.J., 2008. Utility of psbA and nSSU for phylogenetic reconstruction in the Corallinales based on New Zealand taxa. Mol. Phylogenet. Evol. 46, 958-973.

Cabioch, J., 1972. Etude sur les Corallinacees. II. La morphogenese: consequences systematiques et phylogenetiques. Cah. Biol. Mar. 13, 137-288.

Cabioch, G., Montaggioni, L., Franck, N., Seard, C., Salle, E., Payri, C.E., Pelletier, B., Paterne, M., 2008. Successive reef depositional events along the Marquesas foreslopes (French Polynesia) since 26 ka. Mar. Geol. 250, 157-179.

Cabioch, J., 1988. Morphogenesis and generic concepts in coralline algae-a reappraisal. Botanica 49, 493-509, Botanica 49,1-98.

Campbell, S.J., Woelkerling, W.J., 1990. Are Titanoderma and Lithophyllum (Corallinaceae, Rhodophyta) distinct genera? Phycologia 29, 114-125.

Felsenstein, J., 1985. Confidence limits on phylogenies: an approach using the bootstrap. Evolution 39, 783-791.

Guiry, M.D., Guiry, G.M., 2011. AlgaeBase. World-Wide Electronic Publication, National University of Ireland, Galway. $<$ http://www.algaebase.org $>$.

Harper, J.T., Saunders, G.W., 2001a. Molecular systematics of the Florideophyceae (Rhodophyta) using nuclear large and small subunit rDNA sequence data. J. Phycol. 37, 1073-1082.

Harper, J.T., Saunders, G.W., 2001b. The application of sequences of the ribosomal cistron to the systematics and classification of the florideophyte red algae (Florideophyceae, Rhodophyta). Cah. Biol. Mar. 42, 25-38.

Harper, J.T., Saunders, G.W., 2002. A re-classification of the Acrochaetiales based on molecular and morphological data, and establishment of the Colaonematales ord. nov. (Florideophyceae, Rhodophyta). Eur. J. Phycol. 37, 463-476.

Harvey, A.S., Broadwater, S.T., Woelkerling, W.J., Mitrovski, P.J., 2003. Choreonema (Corallinales, Rhodophyta): 18S rDNA phylogeny and resurrection of 
the Hapalidiaceae for the subfamilies Choreonematoideae, Australithoideae, and Melobesioideae. J. Phycol. 39, 988-998.

Hughey, J.R., Braga, J.C., Aguirre, J., Woelkerling, W.J., Webster, J.M., 2008. Analysis of ancient DNA from fossil corallines (Corallinales, Rhodophyta). J. Phycol. $44,374-383$.

Hurvich, C.M., Tsai, C.L., 1989. Regression and time series model selection in small samples. Biometrika 76, 297-307.

Johansen, H.W., 1976. Current status of generic concepts in coralline algae (Rhodophyta). Phycologia 15, 221-244.

Kato, A., Baba, M., Suda S., 2009. A Systematic Study of Crustose Coralline Alga Neogoniolithon brassica-florida in the Ryukyu islands, Japan. In: Poster at the IPC9 (2nd-8th August, Tokyo, Japan).

Keats, D.W., Chamberlain, Y.M., Baba, M., 1997. Pneophyllum conicum (Dawson) comb. nov. (Rhodophyta, Corallinaceae), a widespread Indo-Pacific non- genienlate coralline alga that overgrows and kills coral. Bot. Mar. 40, 263-279.

Kostka, M., Uzlikova, M., Cepicka, I., Flegr, J., 2008. SlowFaster, a user-friendly program for slow-fast analysis and its application on phylogeny of Blastocystis. BMC Bioinform. 9, 341.

Lamy, D., Woelkerling, W.J., 1998. The Paris Museum and non-geniculate coralline systematics. In: Woelkerling, W.J., Lamy, D. (Eds.), Non-geniculate Coralline Red Algae and the Paris Museum: Systematics and Scientific History. Publications Scientifiques du Museum/A.D.A.C, Paris, pp. 15-242.

Le Gall, L., Dalen, J.D., Saunders, G.W., 2008. Phylogenetic analyses of the red algal order Rhodymeniales supports recognition of the Hymenocladiaceae fam. nov., Fryeellaceae fam. nov., and Neogastroclonium gen. nov. J. Phycol. 44, 15561571.

Le Gall, L., Payri, C.E., Bittner, L., Saunders, G.W., 2010. Multigene phylogenetic analyses support recognition of the Sporolithales ord. nov. Mol. Phylogenet. Evol. 54, 302-305.

Le Gall, L., Saunders, G.W., 2007. A nuclear phylogeny of the Florideophyceae (Rhodophyta) inferred from combined EF2, small subunit and large subunit ribosomal DNA: establishing the Corallinophycidae subclassis nov. Mol. Phylogenet. Evol. 43, 1118-1130. 
Le Gall, L., Saunders, G.W., 2010. DNA barcoding is a powerful tool to uncover algal diversity: a case study of the Phyllophoraceae (Gigartinales, Rhodophyta) in the Canadian flora. J. Phycol. 46, 374-389.

Maddison, W., Maddison, D., 2003. MacClade, v. 4.06, Sinauer Associates. Maddison, W., Maddison, D., 2006. Mesquite: a modular system for evolutionary analysis. Version 2.6. <http://mesquiteproject.org >.

Maneveldt, G.W., 2005. A Global Revision of the Nongeniculate Coralline Algal Genera Porolithon Foslie (Defunct) and Hydrolithon Foslie (Corallinales, Rhodophyta). PhD manuscript, University of the Western Cape, Bellville, South Africa. pp 520 (pls 187).

Maneveldt, G.W., Keats, D.W., 2008. Effects of herbivore grazing on the physiognomy of the coralline alga Spongites yendoi and on associated competitive interactions. Afr. J. Mar. Sci. 30, 581-593.

Medina-Pons, F.J., Terrados, J., Lopez-Lopez, A., Yarza, P., Rossello-Mora, R., 2009. Evaluation of the $18 \mathrm{~S}$ rRNA clone library approach to study the diversity of the macroeukaryotic leaf-epiphytic community of the seagrass Posidonia oceanica (L.). Delile. Mar. Biol. 156, 1963-1976.

Payri, C.E., 1995. Production carbonatee de quelques algues calcifiees sur un recif corallien de Polynesie fran^^aise". Bull. Soc. Geol. Fr. 166 (1), 77-84.

Payri, C.E., Cabioch, G., 2003. The systematics and significance of coralline red algae in the rhodolith sequence of the Amedee 4 drill core (South-West New- Caledonia). Palaeogeogr. Palaeoclimatol. Palaeoecol. 204, 187-208.

Penrose, D., Woelkerling, W.J., 1992. A reappraisal of Hydrolithon and its relationship to Spongites (Corallinaceae, Rhodophyta). Phycologia 31, 81-88.

Posada, D., 2008. JModelTest: phylogenetic modelaveraging. Mol. Biol. Evol. 25, $1253-1256$.

Pueschel, C.M., 1989. An expanded survey of the ultrastructure of red algal pit plugs. J. Phycol. 25, 625-636.

Ratnasingham, S., Hebert, P.D.N., 2007. BOLD: the barcode of life data system. Mol. Ecol. Note 7, 355-364. 
Rokas, A., Carroll, S.B., 2005. More genes or more taxa? The relative contribution of gene number and taxon number to phylogenetic accuracy. Mol. Biol. Evol. 90, 13371344 .

Saunders, G.W., 1993. Gel purification of red algal genomic DNA: an inexpensive and rapid method for the isolation of polymerase chain reaction-friendly DNA. J. Phycol. 29, 251-254.

Saunders, G.W., 2005. Applying DNA barcoding to red macroalgae: a preliminary appraisal holds promise for future applications. Philos. Trans. R. Soc. London, B 360, 1879-1888.

Saunders, G.W., Bailey, J.C., 1997. Phylogenesis of pit-plug-associated features in the Rhodophyta: inferences from molecular systematic data. Can. J. Bot. 75,14361447.

Saunders, G.W., Kraft, G.T., 1994. Small-subunit rRNA gene sequences from representatives of selected families of the Gigartinales and Rhodymeniales (Rhodophyta). 1. Evidence for the Plocamiales ord. nov. Can. J. Bot. 72, 12501263.

Saunders, G.W., Kraft, G.T., 1996. Small-subunit rRNA gene sequences from reprensentatives of selected families of the Gigartinales and Rhodymeniales (Rhodophyta). 2. Recognition of the Halymeniales ord. nov.. Can. J. Bot. 74,694707.

Saunders, G.W., Lehmkuhl, K.V., 2005. Molecular divergence and morphological diversity among four cryptic species of Plocamium (Plocamiales, Florideophyceae) in northern Europe. Eur. J. Phycol. 40, 293-312.

Schwarz, G., 1978. Estimating the dimension of a model. Ann. Stat. 6, 461-464.

Setchell, W.A., 1943. Mastophora and the Mastophoreae: genus and subfamily of Corallinaceae. Proc. Natl. Acad. Sci. U. S. A. 29, 127-135.

Silva, P.C., Johansen, H.W., 1986. A reappraisal of the order Corallinales (Rhodophyceae). Brit. Phycol. J. 21, 245-254.

Shavit, L., Penny, D., Hendy, M.D., Holland, B.R., 2007. The problem of rooting rapid radiations. Mol. Biol. Evol. 24, 2400-2411.

Stamakis, A., 2006. RAxML-VI-HPC: maximum likelihood-based phylogenetic analyses with thousands of taxa and mixed models. Bioinformatics 22, 26882690.

Stamatakis, A., Hoover, P., Rougemont, J., 2008. A rapid bootstrap algorithm for the RAxML Web-servers. Sys. Biol. 75, 758-771. 
Steneck, R.S., 1986. The ecology of coralline algal crusts: convergent patterns and adaptive strategies. Am. Rev. Ecol. Syst. 17, 273-303.

Steneck, R.S., Adey, W.H., 1976. The role of environment control of morphology in Lithophyllum congestum, a Caribbean algal ridge builder. Bot. Mar. 19, 197215.

Townsend, R.A., Huisman, J.M., 2004. Epulo multipedes gen. et. sp. nov. (Corallinaceae, Rhodophyta), a coralline parasite from Australia. Phycologia 43, 288295.

Verbruggen, H., Maggs, C.A., Saunders, G.W., Le Gall, L., Yoon, H.S., De Clerck, O., 2010. Data mining approach identifies research priorities and data requirements for resolving the red algal tree of life. BMC Evol. Biol. 10,16.

Verheij, E., 1993. The genus Sporolithon (Sporolithaceae fam. nov., Corallinales, Rhodophyta) from the Spermonde Archipelago, Indonesia. Phycologia 32,184196.

Verheij, E., 1994. Nongeniculate Corallinaceae (Corallinales, Rhodophyta) from the Spermonde Archipelago, SW Sulawesi, Indonesia. Blumea 39, 95-137.

Walker, R.H., Brodie, J., Russell, S., Irvine, L.M., Orfanidis, S., 2009. Biodiversity of Coralline algae in the north-eastern Atlantic including Corallina caespitosa sp. nov. (Corallinoideae, Rhodophyta). J. Phycol. 45, 287-297.

Woelkerling, W.J., 1988. The coralline red algae : an analysis of the genera and subfamilies of nongeniculate Corallinaceae. Brithish Museum (Natural History), London and Oxford University Press, Oxford, 268 pp.

Woelkerling, W.J., Campbell, S.J., 1992. An account of the southern Australian species of Lithophyllum (Corallinaceae, Rhodophyta). Bull. Brit. Mus. (Nat. Hist.) Bot. 22, 1-107.

Woelkerling, W.J., Ducker, S.C., 1987. Lesueuria minderiana gen. et sp. nov. (Corallinaceae, Rhodophyta) from southern and western Australia. Phycologia 26, 192-204.

Woelkerling, W.J., Irvine, L.M., 1986. The neotypification and status of Mesophyllum (Corallinaceae, Rhodophyta). Phycologia 25, 379-396.

Woelkerling, W.J., Irvine, L.M., 2007. The genus Mesophyllum (Hapalidiaceae, Corallinales, Rhodophyta): typification update. Phycologia 46, 230-231. 
Woelkerling, W.J., Irvine, L.M., Harvey, A.S., 1993a. Growth-forms in non-geniculate coralline red algae (Corallinales, Rhodophyta). Aust. Syst. Bot. 6, 277-293.

Woelkerling, W.J., Penrose, D., Chamberlain, Y.M., 1993b. A reassessment of type collections of non-geniculate Corallinaceae (Corallinales, Rhodophyta) described by C. Montagne and L. Dufour, and of Melobesia brassica-florida Harvey. Phycologia 32, 323-331.

Yoon, H.S., Hackett, J.D., Bhattacharya, D., 2002. A single origin of the peridininand fucoxanthin-containing plastids in dinoflagellates through tertiary endosymbiosis. Proc. Natl. Acad. Sci. U. S. A. 99,11724-11729. 